\title{
Migrânea e comportamento suicida: cronificação como mecanismo intermediário e associação com depressão e sintomas cognitivo-comportamentais no ataque
}

\author{
Nikolai José Eustátios Kotsifas (D), Marco Antonio Takashi Utiumi (D), Luiz Carlos Canalli Filho (D), \\ João Guilherme Bochnia Küster (iD, Keryn Sporh Godk (D), Maria Luiza dos Santos (iD, Elcio Juliato Piovesan
}

Universidade Federal do Paraná, Paraná, Brasil

\section{Introdução}

A migrânea é frequentemente associada à ideação/tentativa de suicídio na literatura, porém, há uma carência de estudos nacionais.

\section{Objetivos}

Explorar a associação entre comportamento suicida e migrânea em três centros nacionais.

\section{Material e métodos}

Estudo transversal em ambulatórios especializados. Pacientes com migrânea episódica (ME) e crônica (MC) foram convidados consecutivamente. Acompanhantes, funcionários e pacientes de ambulatórios de Dermatologia sem cefaleia foram convidados como controles. A ideação suicida (IS) foi pesquisada pelas escalas Patient Health Questionnaire-9 (PHQ-9, últimas duas semanas) e Columbia-Suicide Severity Rating Scale (C-SSRS, últimos dois meses). A tentativa de suicídio (TS) ao longo da vida foi explorada pela C-SSRS. Aprovado pelo CEP/HC/UFPR 2.732.610.

\section{Resultados}

Incluímos 297 indivíduos (MC 116, ME 101, controle 80) dos quais 41-57 (PHQ-9 e C-SSRS; 13,8-19,2\%) com IS e $35(11,8 \%)$ com TS. A proporção de IS foi maior no grupo MC em relação aos controles (PHQ-9: 21,6\% vs. 6,2\% $p=0,006$; C-SSRS: $26,7 \%$ vs. 10,0\% p=0,005; regressão simples) e, pela PHQ-9, em comparação com ME (21,6\% vs. $10,9 \% \mathrm{p}=0,038)$. A proporção de TS foi marginalmente superior em $M C$ comparados com controles $(17,2 \%$ vs. $7,5 \% \mathrm{p}=0,054)$. Para a análise multivariada agregamos a ocorrência de IS e/ou TS como comportamento suicida (CS) e, para fins de inferência causal, ajustamos cinco confundidores de acordo com um gráfico acíclico dirigido. A probabilidade de CS sofre efeito da MC em comparação com controles (OR 2,69; IC95\% 1,23-6,24). Um modelo preditivo com o subgrupo migranoso demonstrou que depressão (OR 4,48; IC95\% 2,12-9,78) e piora de sintomas cognitivo-comportamentais (OR 1,42; IC95\% 1, 12-1,83) no ataque estão associados com CS.

\section{Conclusões}

A cronificação parece ter um papel no surgimento do comportamento suicida em migranosos. Depressão e sintomas cognitivo-comportamentais no ataque servem como sinais de alerta.

Palavras-chave: Migrânea, Suicídio, Brasil, Cognição, Sintomas comportamentais 